\title{
Two worlds apart: religion and ethics
}

\author{
Julian Savulescu Murdoch Institute, Royal Children's Hospital, Melbourne, Victoria, Australia
}

\begin{abstract}
In a recent article entitled, Requests "for inappropriate" treatment based on religious beliefs, ${ }^{1}$ Orr and Genesen claim that futile treatment should be provided to patients who request it if their request is based on a religious belief. I claim that this implies that we should also accede to requests for harmful or cost-ineffective treatments based on religious beliefs.

This special treatment of religious requests is an example of special pleading on the part of theists and morally objectionable discrimination against atheists. It also provides an excellent illustration of how different the practices of religion and ethics are.

(Fournal of Medical Ethics 1998;24:382-384)
\end{abstract}

Keywords: Religion; discrimination; futility; equality; justice; harm; autonomy; limitation of treatment

In a recent article in the journal, ${ }^{1}$ Orr and Genesen claim that:

1. "Persistent requests based on deeply held religious beliefs should most often be honoured."2

2. "Treatment which the physician considers 'inappropriate' for some individuals when based purely on personal preference may, in fact, be 'appropriate' when based on a patient's religious belief." 3

They give no argument for these claims except to assert that religious values are special because they deal with the meaning of life and death ${ }^{4}$ and they cite Wreen's earlier assertions that religious values are special because they have a "supremely important integrating and reconciling function".5 This short reply argues that these claims are an example of religious prejudice and special pleading which is offensive to atheists and treats them as second-class citizens.

The authors stipulate that other faith traditions are outside the scope of their article. But why? Unless the authors also believe that there is something special about these religions, one can only suspect that they are simply attempting to appeal to intuitions shared by many readers of these faith traditions. Consider the following three pairs of cases:

1a. An African woman requests infibulation - the excision of her clitoris and sewing together of her labia - because this is a part of her cultural tradition.

1b. A Greek woman requests that her labia be sewn together because her husband believes

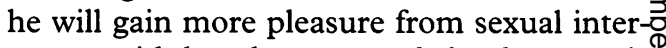
course with her that way and she desperately wants to please him.

2a. A three-year-old girl is involved in a car aco्ف dent and is diagnosed as being brain def. Her parents refuse to allow her to be taken off the ventilator because according to their reli-o gious tradition, a person is dead when theo heart and lungs have stopped working, and $\stackrel{\mathbb{Q}}{\varrho}$ nothing further can be done. They are also $\overrightarrow{\overrightarrow{0}}$ absolutely opposed to organ donation. The 3 intensive care unit is full and another girl is brought in critically injured. With immediate intensive care, there is a good chance she will recover. Her parents are atheists. (They: accept that a person is dead when her brain is 3 dead and that organ donation is a good thing.)

2b. A man is in a persistent vegetative state. He previously completed a living will demandingo treatment if he ever entered such a state because he said that he did not believe in ano afterlife, that he judged that this state was not worse than death, and that there was alwayser some chance of recovery or cure, no matter 0 how small. "It is in my interests," he said, "to to be kept alive."

3a. A woman has a third relapse of leukaemiao after two bone marrow transplants. Her doctors say her chance of surviving are less than? one in a million. The health authority respon-? sible for funding this treatment claim that they cannot afford another transplant in these $\frac{\mathbb{Q}}{\mathbb{Q}}$ circumstances. She requests another bone@ marrow transplant because she says that a? miracle will occur. 
3b. The same as $3 a$ except this woman is an atheist who believes that the risks are worth taking, and she doesn't care about the people who will be denied treatment if she uses up scarce resources in this way. She has no sense of social justice.

While some religious fundamentalists consume scarce community resources, waiting for miracles, receiving futile treatment, other people are dying or being denied scarce effective medical treatment, as case 2a most starkly illustrates. One pre-condition of living in a liberal society is a tolerance of other conceptions of the good life, and not harming others by consuming more than one's own fair share of public goods. The authors' arguments apply equally to cost-ineffective (case $3 \mathrm{a}$ ) and harmful interventions. Should doctors mutilate their patients if they request it, as in case $1 \mathrm{a}$ ? If religious requests are special, do Orr and Genesen believe that we should accede to these requests?

If the authors are saying anything novel, they must be saying that we should treat the patient in $1 \mathrm{a}, 2 \mathrm{a}, 3 \mathrm{a}$, but not in at least one of $1 \mathrm{~b}, 2 \mathrm{~b}, 3 \mathrm{~b}$ insofar as the latter are based on mere "personal preferences". My claim is that there is no reason to treat $1 \mathrm{a}, 2 \mathrm{a}, 3 \mathrm{a}$ any differently from $1 \mathrm{~b}, 2 \mathrm{~b}, 3 \mathrm{~b}$. If one person receives treatment with a one in a million chance, there is prima facie reason to believe that any person with a one in a million chance is entitled to treatment, regardless of her reasons for wanting treatment and motivations.

\section{Principle of equality}

According to Aristotle's Principle of Equality, we should treat like cases alike, unless there is a relevant difference. What could the relevant difference be between patients in these pairs of cases? The fact that one has a religious reason and the other does not is not a relevant difference. This gives special treatment to theists for no good reason. This is a form of discrimination, religious prejudice. On the authors' scheme, those who hold irrational and false beliefs receive preferential treatment over those who hold what atheists believe to be true beliefs. Those who are motivated by adherence to a Judaeo-Christian religious code are given preference over those motivated by self-interest that happens not to be religiously supported.

According to the objectivist view of reasons which I hold, whether a person should be offered a treatment turns on the objective values of the physical circumstances of that person's situation, such as the chance of prolonging a life in which a person can carry on worthwhile relationships with others, achieve worthwhile goals, and so on. Given that there are no differences in objective values promoted or not promoted in each pair of my imaginary cases, there is no reason to prefer the religiously motivated requests.

According to a subjectivist account of reasons, whether a person should be offered treatment would turn on the degree to which that person values that treatment or the degree to which treatment promotes his subjective values. However, again, there is no reason to give preference to religious values over non-religious values per se. Nonreligious values can perform the same "integrating and reconciling" function in atheist lives as religious values can perform for theists.

\section{Appeal to miracles}

If anything, there is less reason to respect religious requests that are based on irrational beliefs. The irrationality of the religious beliefs in these examples is most clearly seen in the case of the woman who expects a miracle (3a). When someone says: "God will cure my leukaemia with this bone marrow transplantation", she is making an empirical claim that is either true or false. Let's assume that her doctors believe it is false. Either she is right or they are right. Since there is no good reason to believe that her leukaemia will be cured, her belief is irrational and likely false. The appeal to miracles is also inconsistent with the central tenets of Christian faith. Firstly, predicting that a miracle will occur presumes that the person knows God's will. Secondly, God has supposedly raised people from the dead so death should be no obstacle to a miracle occurring.

The call to give religious belief special treatment arises from a serious confusion about the relationship between religion and ethics. Religion and ethics are different categories of human enquiry. Religion is as different from ethics as it is from mathematics. Religion is about faith; ethics is about reason. For ethics, religious values are just another set of values, to be treated in the same way as other relevantly similar values. Religion is about what biblical texts, traditions and figureheads say is right and wrong, and what some theists believe is right and wrong. Ethics is about what is right and wrong, about what we have reason to do, what we should do. Indeed, nothing could better display the difference between religion and ethics than this paper by Orr and Genesen, which asserts without any valid argument that religious values should be given special treatment, flouting principles of nonmaleficence and distributive justice. Ethics should treat this special pleading by theists in the same way as special pleading by other groups.

In the end, I find it incredible that, after so many years of struggle against various forms of discrimination, two professional ethicists should 
suggest that some religious fundamentalist be placed above the constraints of distributive justice and professional practice standards that apply to the rest of us, and receive the futile, harmful or cost-ineffective treatment he wants, and that I should not, because he holds, as I see matters, false and irrational beliefs, while I do not.

Fulian Savulescu, BMedSci, MB, BS, PhD, is Associate Professor and Director of the Ethics Program at the
Murdoch Institute, Royal Children's Hospital, Melbourne, Victoria, Australia.

\section{References}

1 Orr RD, Genesen L.B. Requests for "inappropriate" treatment based on religious beliefs. Fournal of Medical Ethics 1997;23:142-7.

2 See reference 1: 146

3 See reference 1: 146-7.

4 See reference 1: 147

5 Wreen MJ. Autonomy, religious values and refusal of treatment. Fotrnal of Medical Ethics 1991;17:124-30.

\section{News and notes}

\section{Ethics and Palliative Care}

An Advanced European Bioethics Course, Ethics and Palliative Care, will be held from 8-10 April, 1999, in Nijmegen, The Netherlands. Subjects: Evolution of palliative care; Ethics and pain management; Limits of palliative care; Futility of medical treatment; Palliative care and euthanasia.

For more information please contact: Dr B Gordijn,
Catholic University Nijmegen, 232 Department of Ethics, Philosophy and History of Medicine, PO Box 9101 , 6500 HB Nijmegen, The Netherlands. Tel: (31) 24-3615320; fax: (31) 24-3540254; e-mail: b.gordijn $a$ efg.kun.nl

Internet site: http://www.azn.nl/fmw/onderwys ukpallia.htm

\section{News and notes}

\section{4th European Forum on Quality Improvement in Health Care and the 4th Swedish OUL Conference}

The 4th European Forum on Quality Improvement in Health Care and the 4 th Swedish OUL Conference will be held in Stockholm, Sweden from 25 - 27 May, 1999.

The forum aims: to provide education on how to improve health care; to exchange sound, practical ideas on improving health care; to provide a setting for deep discussion and shared learning among those charged with leading improvements in health care; to build the scientific base of methods to improve health care; to accelerate the improvement of health care, and to make change happen.

For further information please contact: Marchella Mitchell, British Medical Association, Conference Unit, BMA House, Tavistock Square, London WC1H 9JP, United Kingdom. Tel: +44(0)171 383 6478; fax: +44 (0) 171383 6869; e-mail: MMitchell $a$ bma.org.uk 